\title{
Hot deformation behaviour of bamboo leaf ash-silicon carbide hybrid reinforced aluminium based composite
}

\author{
Kenneth Kanayo Alaneme ${ }^{1, *}$, Saheed Adeoye Babalola ${ }^{1}$, Lesley Heath Chown ${ }^{2}$, and Michael Oluwatosin Bodunrin ${ }^{1,2,3}$ \\ ${ }^{1}$ Materials Design and Structural Integrity Research Group, Department of Metallurgical and Materials Engineering, Federal \\ University of Technology, Akure, PMB 704, Nigeria \\ ${ }^{2}$ School of Chemical and Metallurgical Engineering, African Materials Science and Engineering Network (AMSEN) and DST-NRF \\ Centre of Excellence in Strong Materials; all University of the Witwatersrand, Private Bag 3, WITS, 2050 Johannesburg, South \\ Africa \\ 3 The African Academy of Sciences (AAS), P.O. Box 24916-00502, Nairobi, Kenya
}

Received: 19 February 2020 / Accepted: 21 April 2020

\begin{abstract}
Isothermal compression testing of BLA-SIC hybrid reinforced Aluminium composites was performed on Gleeble 3500 thermomechanical simulator under different deformation temperatures $\left(300-400{ }^{\circ} \mathrm{C}\right)$ and strain rates $\left(0.01-1 \mathrm{~s}^{-1}\right)$. The flow behaviour and the softening mechanisms were established using the trend of the stress-strain curves, activation energy and microstructural examination. The results showed that flow stress increased with decreasing temperature; but was not entirely strain rate sensitive - a characteristic identified in some Al 6XXX based metallic systems. Also, uncharacteristic flow stress oscillations were observed at strain rates of 0.01 and $0.1 \mathrm{~s}^{-1}$ while steady state flow stress was observed at $1 \mathrm{~s}^{-1}$. The hot working activation energy was $\sim 290.5 \mathrm{~kJ} / \mathrm{mol}$ which was intermediate to the range of $111-509 \mathrm{~kJ} / \mathrm{mol}$ reported in literature for various $\mathrm{Al}$ based composites. It was proposed that at strain rates of 0.01 and $0.1 \mathrm{~s}^{-1}$, dynamic recrystallization and/or dislocations-reinforcements interactions were the dominant deformation mechanism(s), while at $1 \mathrm{~s}^{-1}$, dynamic recovery was predominant.
\end{abstract}

Keywords: Al6063/BLA-SiC composite / hot deformation / flow stress / softening mechanism / microstructure / compression testing / constitutive equation

\section{Introduction}

One of the most significant and enduring achievements in the science and technology of metal matrix composite is the validation of the viability of agrowaste derivatives as suitable substitutes/complements to conventional reinforcements for the development of composites. In Aluminium matrix composites (AMCs), the addition of reinforcements is usually targeted at improving the property spectra of the matrix through improved specific strength and stiffness, dimensional stability, corrosion and wear resistance $[1,2]$. This is geared towards enhancing the versatility and applicability of the matrix for industrial and technological purposes [3,4]. It is important to note that AMCs developed with reinforcements made solely or complementarily with the use of agro waste ashes derived from rice huck, bamboo leaves, baggase, groundnut shell, cocoanut shell, among others; have been found to match the core service properties required of AMCs [5]. Their competences for varied technological and industrial

\footnotetext{
* e-mail: kalanemek@yahoo.co.uk
}

applications have been well investigated; and evidences of their practical utilization for product development reported [6,7]. However, AMCs reinforced with agrowaste ashes, like other conventional ceramic reinforcements are essentially less ductile in nature compared to the unreinforced Al matrix. This factor makes the workability of the AMCs difficult for several component shaping and forming processes $[8,9]$. The corollary is clear - cold processing may be limited to certain component design, and hence hot working would become an inevitable option to improve formability to useful shapes and configurations, and for the enhancement of mechanical properties of the AMCs.

In recent years, several studies have been embarked on to investigate the hot workability of AMCs [10-12]. Studies show that selection of optimal hot working process parameters is predicated on understanding of the flow behaviour of the AMCs, which is dependent on several factors such as the reinforcement type, reinforcement volume fraction, initial microstructure and deformation parameters among others [13]. Despite the existence of huge volumes of published articles on AMCs reinforced with low-cost agro waste derivatives or hybrid reinforcements (that is, used alongside conventional 
reinforcements), hardly can one find articles devoted to understanding the hot deformation behaviour of these grades of AMCs. In the present study, the hot deformation behaviour of aluminium based composite reinforced with 10 wt. \% bamboo leave ash (BLA) and silicon carbide ( $\mathrm{SiC})$ mixed in weight ratio $1: 3$, is investigated. The choice of bamboo leave ash is on account of its high silica content, which can serve as a low-cost partial replacement for $\mathrm{SiC}$ [14]. Alaneme et al. [14] reported that BLA/SiC reinforced AMCs of similar composite compositions showed promise for use in developing high performance - cost effective AMCs. But, similar to sole SiC reinforced AMCs, the ductility levels are generally low, and thus will still require hot working for intricate shape forming of components from the composite. At present nothing is known about the hot deformation behaviour of Aluminium based composites reinforced with bamboo leaf ash and silicon carbide. This study hence is necessary to provide basic understanding of the flow behaviour of this grade of composites. Additionally, the suitable process parameters for forming this composite without compromising the useful engineering properties can be established from this study.

The research questions which this study sets out to provide answers to are: what are the flow characteristics of the hybrid reinforced composite? How is the flow behaviour influenced by temperature, strain rate and strain? What deformation mechanisms superintend during the hot working process? How do the constitutive parameters such as activation energy $(Q)$ and stress exponent $(n)$ compare with those reported for other aluminium matrix composites? Could these constitutive parameters be used in determining the mechanism(s) of flow during the hot working of the composites? It is envisaged that the outcomes from the investigation will provide theoretical insights and practical processing information, useful for hot working of this novel grade of AMC.

\section{Materials and method}

Aluminium (6063) matrix composite reinforced with $8 \mathrm{wt}$. $\% \mathrm{BLA}$ and $\mathrm{SiC}$ with reinforcement weight ratio of $1: 3$, was used as Aluminium based composite for this investigation. The silicon carbide $(\mathrm{SiC})$ particles were of average particle size of $30 \mu \mathrm{m}$ while the bamboo leaf ash (BLA) of particle size $<50 \mu \mathrm{m}$ was derived from controlled burning and sieving of dry bamboo leaves. The bamboo leaf ash processing and composite production procedures have been reported in details by Alaneme et al. [14]. Basically, the process required charge calculation to determine the amounts of the BLA and $\mathrm{SiC}$ (in weight ratio 1:3) which served as reinforcements and $\mathrm{Al} / 6063$ alloy required for the composite development. The $\mathrm{Al} / 6063$ alloy was charged and melted in a furnace, allowed to cool slowly to a semisolid state $\left(\sim 600^{\circ} \mathrm{C}\right)$ before the preheated reinforcements were added and the ensuing mixture, stirred manually. The mixture was then superheated to $750{ }^{\circ} \mathrm{C} \pm 20^{\circ} \mathrm{C}$, and stirred a second time, using a mechanical stirrer, operated at $400 \mathrm{rpm}$ for $10 \mathrm{~min}$. The composite was cast into sand moulds inserted with metallic chills, and afterwards, machined to cylindrical specimen configuration with dimensions $10 \mathrm{~mm}$ diameter and $15 \mathrm{~mm}$ length. The isothermal hot compression tests were performed on a Gleeble 3500 thermomechanical simulator at different strain rates $\left(0.001,0.1\right.$, and $\left.1.0 \mathrm{~s}^{-1}\right)$, temperatures $\left(300^{\circ} \mathrm{C}\right.$, $350{ }^{\circ} \mathrm{C}$ and $400^{\circ} \mathrm{C}$ ) and constant global strain of $50 \%$. Prior to hot-compression testing, chromel-alumel thermocouple was attached to the composite sample surface at the centre (mid span) of the length dimension to measure the temperature of the samples during the experiment, following the wrap-round method [15]. The procedure for conducting the test entailed, heating the samples to the predetermined deformation temperatures at a heating rate of $5{ }^{\circ} \mathrm{C} / \mathrm{s}$ and holding at the temperature isothermally for $180 \mathrm{~s}$ to ensure uniform sample temperatures. Friction between the samples and pressure head was ameliorated by application of graphite foil and nickel paste between the samples and pressure head prior to testing. The samples were then compressed until the global strain was attained, at which point the samples were immediately compressed air-cooled to preserve their microstructures. Scanning electron microscopy (SEM), carried out on a Field Emission Scanning Electron Microscope, was used to study the post-deformation microstructures. Prior to microscopy, the samples were ground and polished following standard metallographic procedures and were etched using Keller's reagent.

\section{Results and discussion}

\subsection{Stress-strain behavior}

Figure $1 \mathrm{a}-\mathrm{c}$ shows the flow stress obtained from the isothermal hot compression testing at different deformation temperatures and strain rates. From these figures, some general and unique trends can be observed. On the general trends, the deformed composites showed sensitivity to changes in deformation temperature, but to a limited extent with respect to strain rate. The flow stress increased with increasing strain rate from $0.01 \mathrm{~s}^{-1}$ to $0.1 \mathrm{~s}^{-1}$ but with marginal changes between $0.1 \mathrm{~s}^{-1}$ and $1.0 \mathrm{~s}^{-1}$; while the flow stress showed consistent increase with decreasing deformation temperatures. Increase in flow stress with increase in strain rate is normally expected based on reports by previous authors $[11,16,17]$. Ideally, with increasing strain rate, the pace of dislocation pile up, tangling, and multiplication increases, resulting in increased dislocation density in the material. The increased dislocation density serves as encumbrance to further movement of dislocations, necessitating increased flow stress to sustain plastic deformation $[11,18]$. This behaviour has been rationalised by Mitchell et al. [19] and Zong et al. [20] using equations (1) and (2), which show that strain rate has a direct relationship with the speed of mobile dislocation and flow stress. Therefore, increasing strain rate should result in an increase in flow stress.

$$
\begin{gathered}
\dot{\epsilon}=\rho b A \sigma^{m} \\
\nu=A \sigma^{m}
\end{gathered}
$$



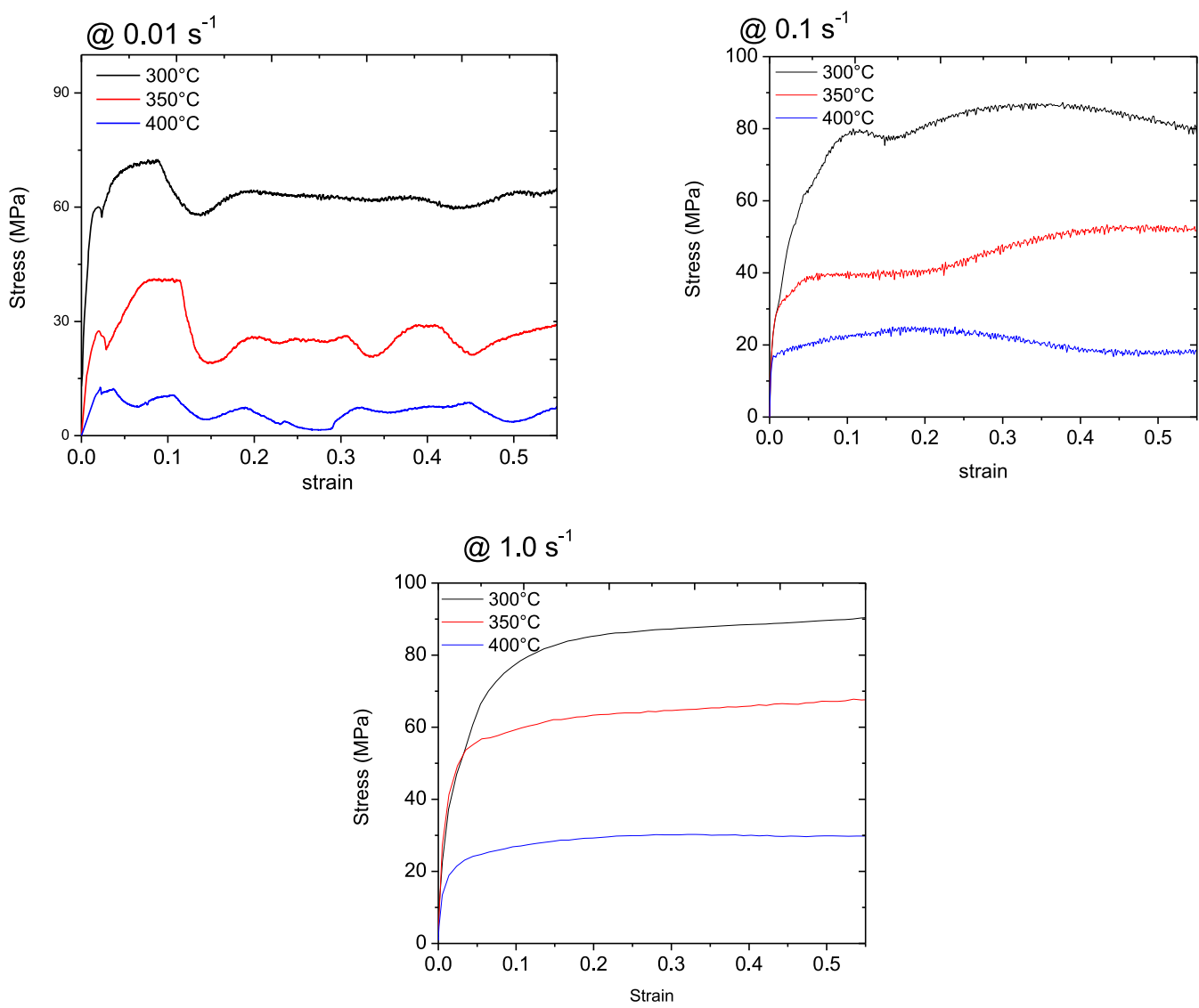

Fig. 1. True stress-true strain curves of $6063 \mathrm{Al} / \mathrm{SiC}_{\mathrm{p}}$ composites under different compression conditions: (a) $0.01 \mathrm{~s}^{-1}$; (b) $0.1 \mathrm{~s}^{-1}$; (c) $1 \mathrm{~s}^{-1}$.

where $\dot{\epsilon}$ is strain rate, $\rho$ is dislocation density, $b$ is burger vector, $v$ is average dislocation velocity, $A$ is a constant, $\sigma$ is flow stress and $m$ is the strain rate sensitivity parameter [19]. However, the results of the present study show that this theory is not without exceptions, as the marginal changes in flow stress between the 0.1 and $1 \mathrm{~s}^{-1}$ seem to indicate. Such strain rate insensitivity has been acknowledged as common with some 5XXX and 6XXX Al alloys, and has been linked to phenomena such as dynamic strain aging (Portevin Le Chantelier effect) facilitated by solute atoms and dislocations interaction [20-22]. In the present study, it was not established what was responsible for the limited strain rate sensitivity observed, and is a subject for further investigation by our research group.

As already pointed out, the flow stress increased consistently with decreasing deformation temperature. The observed increase in flow stress with decrease in deformation temperature can be attributed to the decrease in dislocation mobility at lower deformation temperature on account of the reduced pathways/channels for dislocation motion [23,24]. Under all test conditions, the flow stress increased rapidly at the initial stage of deformation due to the dominance of work hardening [8,18,25], while at the later stage of the deformation (with increased strain), the signatures of flow softening such as a drop-in flow stress or the attainment of a steady-state flow stress became visible $[8,26,27]$.
The unique features observed from the flow stress patterns in Figure 1, are discussed in the succeeding part of this section. At the strain rate of $0.01 \mathrm{~s}^{-1}$ (Fig. 1a), the flow stress increased to a distinct broad peak, followed by a drastic drop in flow stress and finally the appearance of flow stress oscillations at higher strains. At strain of $\sim 0.03$, an initial peak stress was attained before further increase to the main peak stress. This behaviour is more conspicuous at deformation temperatures lower than $400^{\circ} \mathrm{C}$. At the strain rate of $0.1 \mathrm{~s}^{-1}$ (Fig. 1b), the flow stress increased rapidly at very low strain reaching an initial peak stress, thereafter different flow pattern was displayed at the different deformation temperatures. At a temperature of $300^{\circ} \mathrm{C}$, the flow stress decreased slightly after the initial peak stress before rising to a higher second peak stress at about the strain of 0.35 . Then flow stress decreased gradually till the final strain was reached. At $350^{\circ} \mathrm{C}$ the flow curve displayed a nearly steady-state profile after the initial peak stress was reached, then increased gradually to a second higher peak stress at the final strain. At $400^{\circ} \mathrm{C}$, a gradual increase in flow stress to a peak strain of 0.18 was observed followed by a gradual drop in flow stress to a near steady-state condition at the final strain of 0.55 . The trends observed at this strain rate suggest that the oscillation that occurred at the strain rate of 0.1 was suppressed to a large extent. In Figure 1c, at strain rate of $1 \mathrm{~s}^{-1}$, the flow stress increased rapidly up to the strain of $\sim 0.07$, followed by a 
gradual increase towards the peak stress at deformation temperatures of $300^{\circ} \mathrm{C}$ and $350^{\circ} \mathrm{C}$. However, at $400^{\circ} \mathrm{C}$, a steady-state flow stress was reached. The flow stress oscillations that are seen at the lower strain rates $(0.01$ and $0.1 \mathrm{~s}^{-1}$ ) did not occur at $1 \mathrm{~s}^{-1}$ strain rate. The observed flow oscillations are however not typical of classical PLC effect, and thus further investigations will be required. The authors reason that the interaction of dislocations with the reinforcements at low strain rates could be a factor for the observed flow stress pattern. When the dislocations come in contact with the particles, the flow stress required to move the dislocations will increase as the particles serve as barriers to dislocation motion. The flow stress drops as soon as the dislocations are able to cut through the reinforcements, and the process is repeated on encountering of other particles [28]. In such a scenario, the profile created will largely be dependent on the distribution of the particles in the matrix.

\subsection{Dynamic deformation mechanism}

The appearance of broad peaks and flow oscillations of the types observed in Figure 1a and b have been reported as signatures of dynamic recrystallisation by some researchers [29,30-35] while other authors have reported that flow oscillations indicate the occurrence of dynamic strain aging (Portevin-Le Chatelier effect) or cracking of the material during deformation [29,36-38]. The occurrence of cracking in this case is unlikely because flow stress oscillations that is accompanied by cracking of the material usually occur when the materials are deformed under high strain rate conditions typically $>10 \mathrm{~s}^{-1}$. Also, the pattern of the observed flow stress oscillations raises some uncertainties if it is actually due to the PLC effect. As suggested earlier, a factor which could be responsible for the type of flow stress oscillations observed is the interaction of dislocations with the reinforcements at low strain rates. It is posited that the dislocations experience more difficulty moving on encountering the reinforcement particles, thus the flow stress required to move the dislocations will increase as the particles act as barriers to their motion. But the flow stress drops as soon as the dislocations are able to cut through the reinforcements, as they encounter less restrain to motion through the relatively softer Al matrix $[28,39]$. Thus, the profile created will largely be dependent on the distribution of the particles in the matrix. The unravelling of the actual phenomena responsible is a subject for further study by the authors.

Another possible factor for the flow stress oscillations is dynamic recrystallization. $\mathrm{Shi}^{36}$ et al. [40] among several other authors have reported that aluminium alloys have high stacking-fault energy and thus would not undergo dynamic recrystallisation [41,42]. However, empirical evidences supporting the occurrence of dynamic recrystallisation during hot working of pure aluminium, aluminium alloys and aluminium matrix composites have been widely reported [41,43-45]. For example, dynamic recrystallisation is usually favoured at high temperatures and low strain rates and the type of oscillations exhibited by materials during deformation is influenced by strain rate and deformation temperatures. Figure $1 \mathrm{a}$ and $\mathrm{b}$ shows that the occurrence of dynamic recrystallisation is very likely in this material. Similar to the behaviour of many metallic materials, the appearance of steady-state flow stress when the composite was deformed at a strain rate of $1 \mathrm{~s}^{-1}$ at the peak stress suggests dynamic recovery as the dominant softening mechanism. Figure 1c showed that dynamic recovery would be responsible for flow softening at the strain rate of $1 \mathrm{~s}^{-1}$. The different mechanisms suggested by the stress-strain curves in Figure 1 requires detailed microstructural examination in order to establish the dominant deformation mechanism during hot working of the composites.

\subsection{Activation energy for hot working}

The activation energy for hot working $\left(Q_{\mathrm{hw}}\right)$ of materials remains an important parameter because it serves as a measure of material's resistance to deformation $[8,33,46-48]$. It has been used by several researchers to propose the mechanisms controlling the deformation process $[34,49]$. Moreover, it has been used to develop constitutive relationships for predicting flow stress $[16,42,50-52]$. In this work, the $Q_{\mathrm{hw}}$ of the Al6063/ SiC-BLA composites are determined using the Arrhenius hyperbolic-sine equation due to its simplicity and its applicability at both low and high stresses $[26,49,53]$. To determine the $Q_{\mathrm{hw}}$, other constitutive constants such as $n, \alpha, \beta, A$ in the equation, needs to be obtained. These constants are obtained by fitting experimental data following the rearranged (secondary/derivative) hyperbolic-sine equations in (3)-(4) $[32,34,53]$. The different plots showing how each constitutive constant is derived are presented in Figures 2-6.

$$
\begin{gathered}
Z=\dot{\epsilon} \exp (Q \mid R T)=A \sigma^{n} \\
Z=\dot{\epsilon} \exp (Q \mid R T) A_{2} \exp (\beta \sigma) \\
Z=\dot{\epsilon} \exp (Q \mid R T)=A_{3}[\sinh (\sigma \alpha)] \\
\dot{\epsilon}=A[\sinh (\alpha \sigma \rho)]^{n} \exp \left(\frac{-Q}{R T}\right) \quad \text { for all } \sigma
\end{gathered}
$$

where $\beta$, is a constant, $\alpha$ is a material constant and can be determined using the relation $(\sigma=\beta / \alpha), \sigma$ is given as either the peak stress or incremental stress obtained directly from stress-strain flow curves, and $n$ is the stress sensitivity constant. Taking the natural logarithms on both side of equations (3)-(5), and using partial differentiation, on rearranging yields straight line equation. The constant $\tilde{n}$ is obtained from the power law at low stresses (Eq. (3)). $\beta$ is a constant obtained from the exponential law at high stress from (Eq. (4)). The material constant $\alpha$ is the stress multiplier derived from equation (5).

The stress exponent $n$ is obtained from equation (3). The activation energy for hot working is obtained using equation (6), where the slope of the graph of natural logarithm of $\sinh (\alpha \sigma \dot{\rho})$ against $1 / T$ is plotted. 
Plot at 0.1 strain

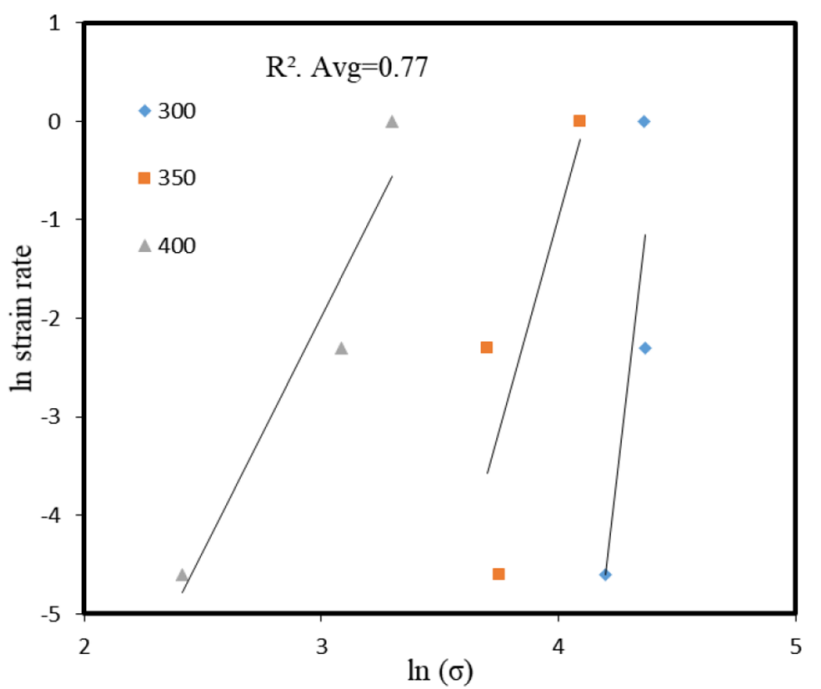

Plot at peak stress

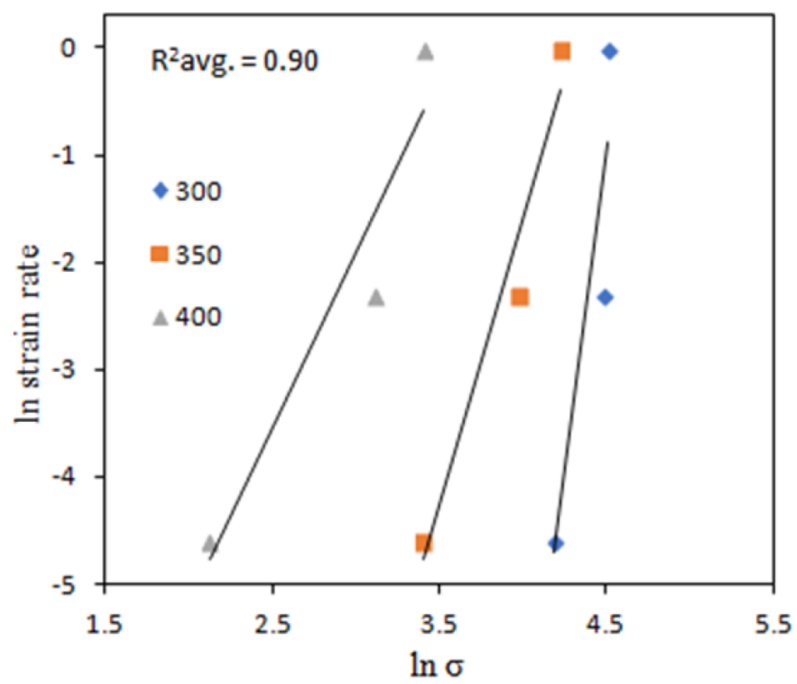

Fig. 2. Plot of In $\dot{\epsilon}$ vs In $\sigma_{p}$.
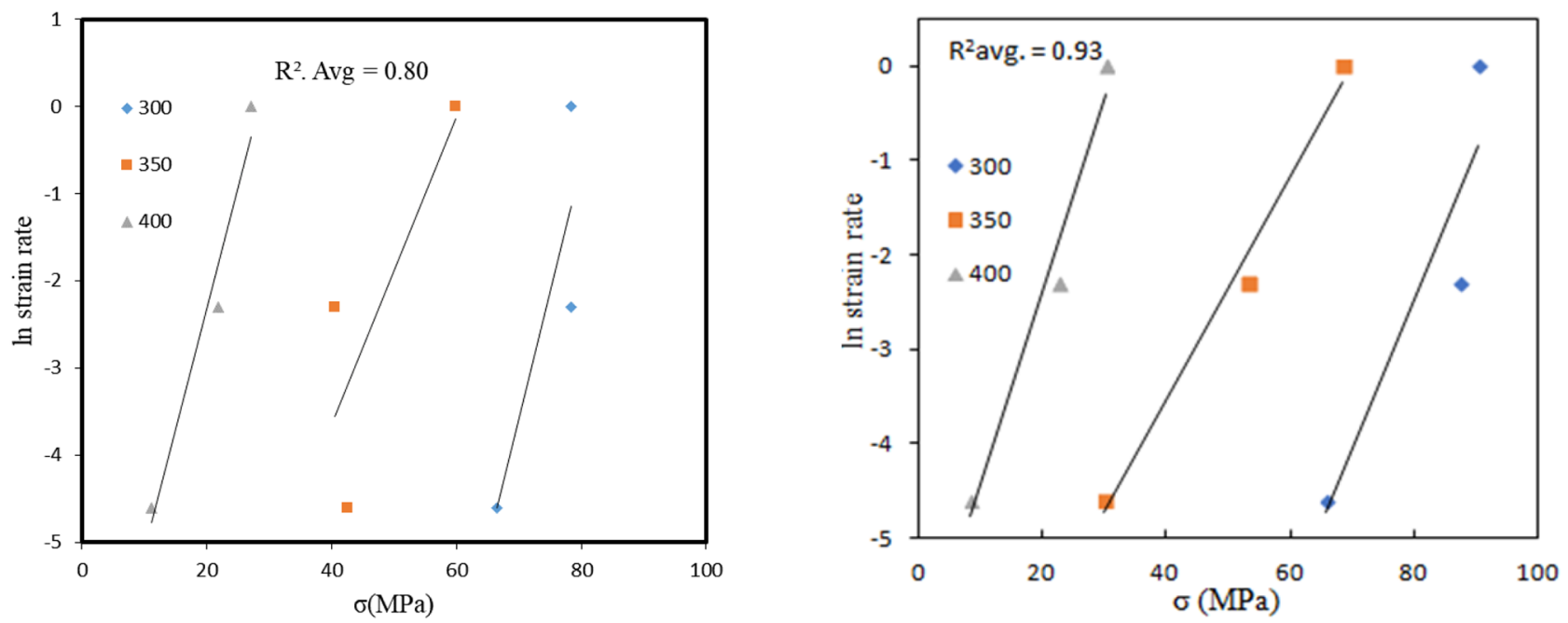

Fig. 3. Plot of In $\dot{\epsilon}$ vs $\sigma_{p}$.
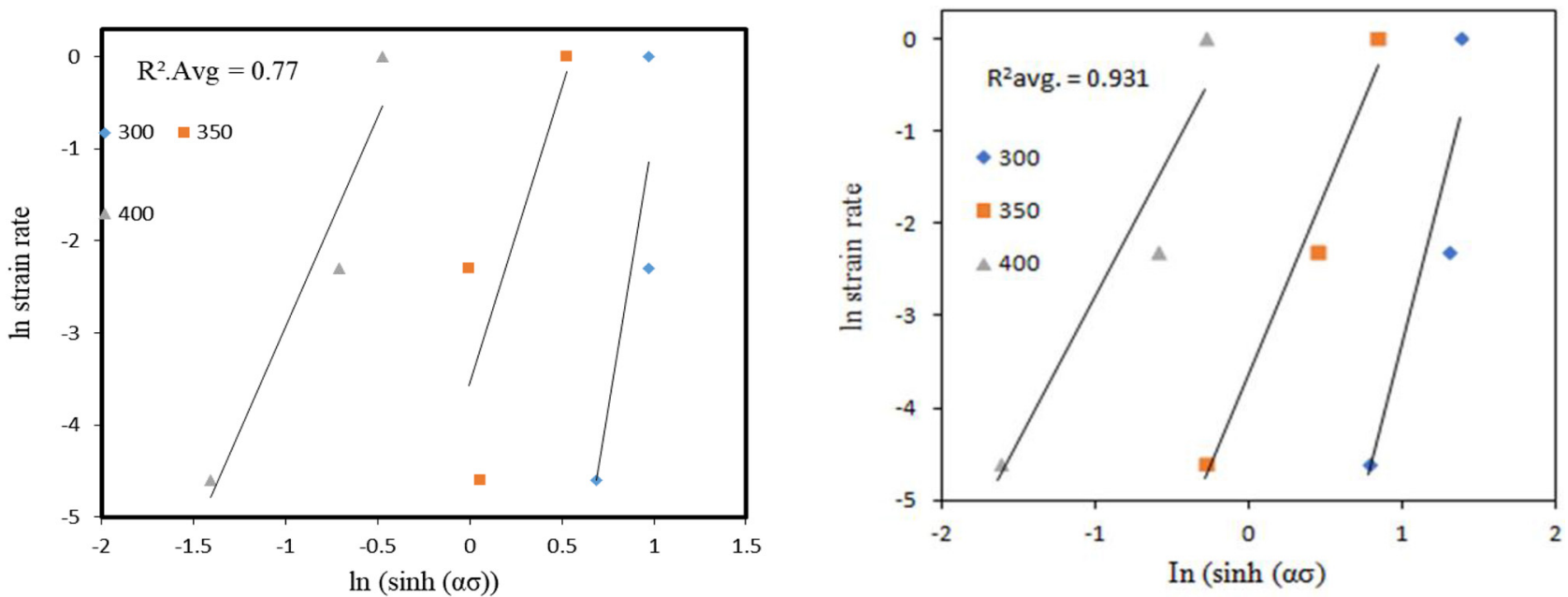

Fig. 4. Plot of In $\dot{\epsilon}$ vs In $\left(\sinh \left(\alpha \sigma_{\rho}\right)\right)$. 

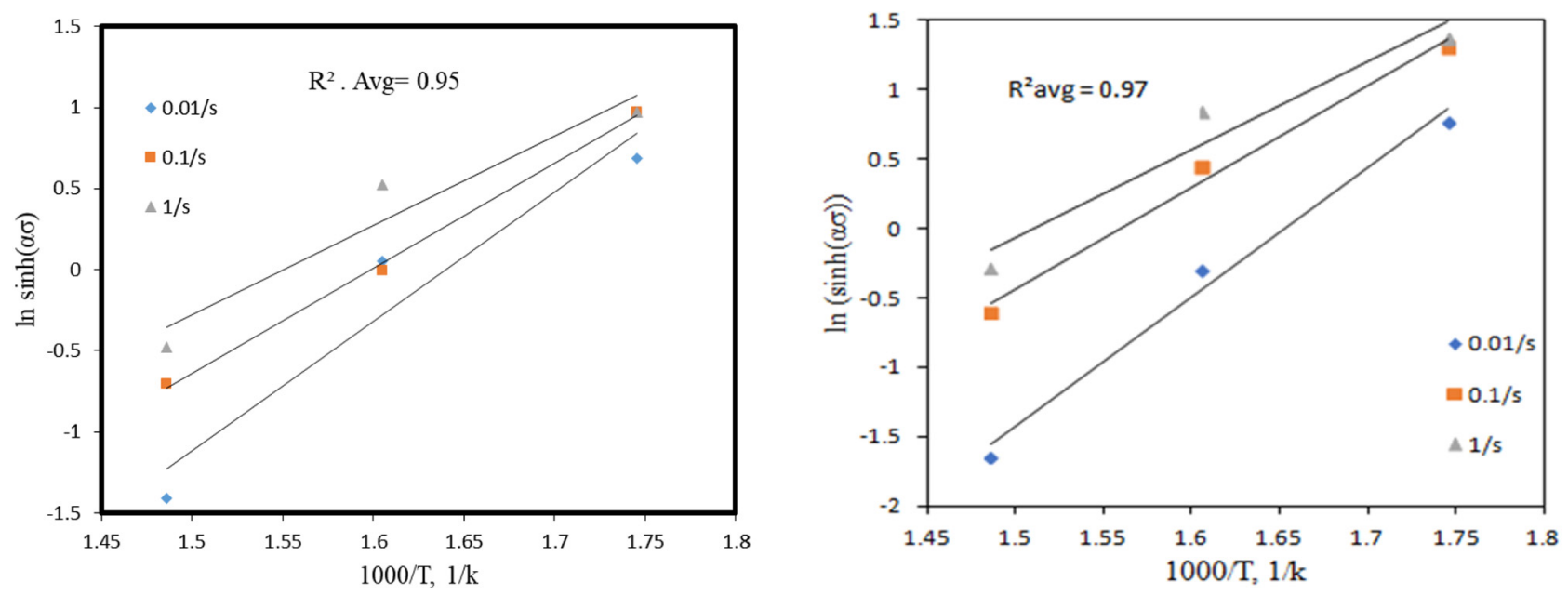

Fig. 5. Plot of $\delta \operatorname{In}\left(\sinh \left(\alpha \sigma_{\mathrm{p}}\right)\right)$ vs $\delta \frac{1}{T}$.
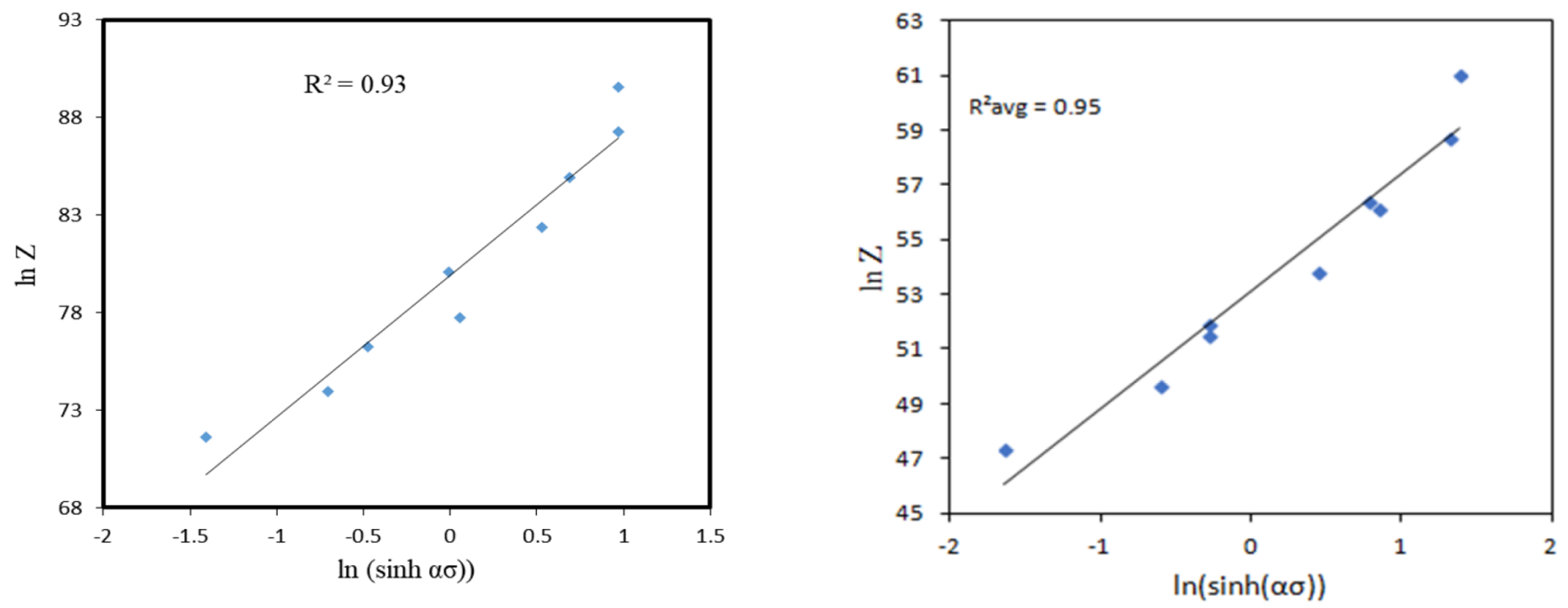

Fig. 6. Plot of In $\mathrm{Z}$ vs $\left\{\operatorname{In} \sinh \left(\alpha \sigma_{\mathrm{p}}\right)\right\}$.

It should be noted that the hyperbolic-sine equation in its original form does not account for the effect of strain [31]. Consequently, there have been divergent views on how best to determine the constitutive constants. Some authors have recommended that the derivation of constitutive constants using the hyperbolic-sine equation should only be done at the steady-state stress [31]. However, it has been long-established that not all materials exhibit steady state flow stress when subjected to hot working [32,54-56]. Consequently, other authors have proposed that constitutive constants could be derived either at peak stress or at incremental strain if the steady-state condition is not met [57-60]. It is clearly evident in Figure $1 \mathrm{a}$ and $\mathrm{b}$ that the steady-state stress condition was hardly met when the aluminium matrix composites were deformed at strain rates lower than $1 \mathrm{~s}^{-1}$. Therefore, in this study, the
Table 1. Flow stress values (MPa) obtained from isothermal compression testing at 0.1 strain.

\begin{tabular}{llll}
\hline Strain rate & $300^{\circ} \mathrm{C}$ & $350{ }^{\circ} \mathrm{C}$ & $400^{\circ} \mathrm{C}$ \\
\hline 0.01 & 66.43 & 42.51 & 11.16 \\
0.1 & 78.45 & 40.47 & 21.91 \\
1 & 78.43 & 59.85 & 27.07 \\
\hline
\end{tabular}

constitutive constants for determining the $\mathrm{Q}_{\mathrm{hw}}$ were derived at both the peak stress and at incremental strains as presented in Figures 2-6.

Tables 1 and 2 show respectively, the flow stress values, and constitutive constants in addition with $Q_{\mathrm{hw}}$ derived at the at incremental strain, while Tables 3 and 4 present the 
Table 2. Material constant derived by fitting the exponential data.

\begin{tabular}{lllll}
\hline STRAIN & $n$ & $\alpha$ & $Q$ & $\ln A$ \\
\hline 0.1 & 7.6942 & 0.0217 & 427 & 79.97 \\
0.2 & 4.7697 & 0.0225 & 297 & 55.10 \\
0.3 & 4.1083 & 0.0248 & 261 & 48.42 \\
0.4 & 2.7049 & 0.0330 & 175 & 30.28 \\
0.5 & 4.2617 & 0.0231 & 302 & 56.12 \\
AVERAGE & 4.7078 & 0.0250 & 292.4 & 53.98 \\
\hline
\end{tabular}

Table 3. Peak stresses at different strain rate and temperature.

\begin{tabular}{llll}
\hline Strain rate & $\mathbf{3 0 0}{ }^{\circ} \mathrm{C}$ & $\mathbf{3 5 0}{ }^{\circ} \mathrm{C}$ & $\mathbf{4 0 0}{ }^{\circ} \mathrm{C}$ \\
\hline $\mathbf{0 . 0 1}$ & 66 & 30 & 8 \\
$\mathbf{0 . 1}$ & 87 & 53 & 23 \\
$\mathbf{1 . 0}$ & 90 & 68 & 30 \\
\hline
\end{tabular}

flow stress values, and constitutive constants in addition with $Q_{\mathrm{hw}}$ that are derived from the peak stresses. It can be seen that the average values of the constitutive constants and $Q_{\mathrm{hw}}$ derived at incremental strain is slightly higher than the values obtained by using the peak stress. However, the difference $(\sim 16.18 \mathrm{~kJ} / \mathrm{mol}$ or $\sim 6 \%)$ is marginal and negligible. This suggests either the average values of the constitutive constants derived at incremental strain or constants derived at peak stress could be used without having significant difference in the interpretation of the results. In both cases, the $Q_{\mathrm{hw}}$ of the Al6063/BLA-SiC composite was higher than the activation energy for selfdiffusion $\left(Q_{\mathrm{sd}}\right)$ of aluminium $(\sim 142 \mathrm{~kJ} / \mathrm{mol})$ by a maximum of $52 \%$. This suggests that mechanisms other than dynamic recovery may have dominated the deformation process. Some studies have suggested that when the $Q_{\mathrm{hw}}$ is higher than $Q_{\text {sd }}$, then dynamic recrystallisation may likely be the deformation mechanism [28,61,62]. McQueen and Ryan [63] reported that the $Q_{\mathrm{hw}}$ in materials that undergo dynamic recovery is usually close to $Q_{\text {sd }}$. This has been confirmed by many other authors who have worked on the hot deformation behaviour of aluminium and its alloys $[39,41,57,64]$. Additionally, McQueen et al. [69] and McQueen and Ryan [65] mentioned that the $Q_{\mathrm{hw}}$ in materials that undergo dynamic recrystallisation could be $20 \%$ higher than activation energy for self-diffusion while it could be up to $50 \%$ higher in materials having solutes, precipitates and reinforcement additions. In this study, the $Q_{\mathrm{hw}}$ of aluminium matrix composites concurs with the reports of McQueen and Ryan [63]. Therefore, the high $Q_{\mathrm{hw}}$ obtained in this study points to the interaction of mobile dislocations with the reinforcing particles in the composites during hot working. Similar reports have been made by Chen et al. [11] and $\mathrm{Xu}$ et al. [66].

Apart from the activation energy, the stress exponent could also give an indication of the mechanisms controlling the deformation process $[24,66]$. Nix [24] reported that
Table 4. Material constant derived at peak stresses.

\begin{tabular}{llll}
\hline$n$ & $\alpha$ & $Q$ & $\ln A$ \\
\hline $\mathbf{4 . 5 7}$ & 0.0231 & 290.5 & 53.086 \\
\hline
\end{tabular}

when the stress exponent values near 5 , the deformation is strictly controlled by mobility of dislocation rather than dislocation substructure. In addition, it was stated that the flow stress of dislocation mobility controlled deformation showed sensitivity to changes in strain rate. The stress exponent obtained from this study is presented in Tables 2 and 4 . It could be seen that the values are close to 5 but the behaviour of the flow stress (Fig. 1a-c) was only sensitive to changes in strain rate at strain rates between 0.01 and $0.1 \mathrm{~s}^{-1}$. Therefore, it could not be firmly established that the hot deformation of this composites is governed by dislocation mobility, since the results at strain rate of $1 \mathrm{~s}^{-1}$ did not show strain rate sensitivity. Table 5 shows the activation energy for hot working that were reported for different aluminium matrix composites. It can be seen that the values obtained in this study fell within the reported range of $110-509 \mathrm{~kJ} / \mathrm{mol}$. The $Q_{\mathrm{hw}}$ indicates the resistance a material poses to deformation. Comparing the $Q_{\mathrm{hw}}$ obtained in this study with previous studies, it can be seen that the Al6063/BLA-SiC has intermediate workability in comparison with the composites presented in Table 5. The activation energy showed that Al6061 based composites with different reinforcements showed lower resistance to deformation when compared with the Al 6063 based composites considered in this study. From hot workability point of view, it implies that A6061 based composites may be easily formed than the Al6063/BLA-SiC composites. However, AMCs such as $\mathrm{Al} / \mathrm{Al}_{2} \mathrm{O}_{3}, 8009 \mathrm{Al} / \mathrm{Al}_{2} \mathrm{O}_{3}$ and $2024 \mathrm{Al} / \mathrm{CNT}$ showed higher resistance to deformation and may be difficult to form when compared with Al6063/BLA-SiC. This trend indicates that the choice of aluminium matrix and reinforcement influences the workability of AMCs. This is similar to the case of metallic alloys where phase constituents and compositions influence the workability of the alloy $[63,67]$. The point of note is that the workability of the Al6063/BLA-SiC composite produced, falls within the range for AMCs which their hot deformation processing characteristics have been reported in literature. 
Table 5. Activation energy and hot working of some commercial and experimental aluminum alloy.

\begin{tabular}{|c|c|c|c|c|}
\hline Composites & $\begin{array}{l}\text { Activation energy } \\
(\mathrm{kJ} / \mathrm{mol})\end{array}$ & $\begin{array}{l}\text { Stress exponent } \\
\text { " } n "\end{array}$ & $\begin{array}{l}\text { Deformation } \\
\text { parameters }\end{array}$ & Reference \\
\hline 6063Al/BLA/SiCp & $\begin{array}{l}290.5 \\
(\sigma \rho \text { based })\end{array}$ & $\begin{array}{l}4.57 \\
(\sigma \rho \text { based })\end{array}$ & $\begin{array}{l}300-400{ }^{\circ} \mathrm{C} \\
0.001-1.0 \mathrm{~s}^{-1}\end{array}$ & This work \\
\hline $6061 \mathrm{Al} / \mathrm{Mg}_{2} \mathrm{~B}_{2} \mathrm{O}_{5} \mathrm{w}$ & 111 & 6.5 & $\begin{array}{l}300-450^{\circ} \mathrm{C} \\
0.001-1.0 \mathrm{~s}^{-1}\end{array}$ & Zhao et al. [68] \\
\hline $6061 \mathrm{Al} / 20 \% \mathrm{SiC}_{\mathrm{w}}$ & 246 & 9.58 & $\begin{array}{l}300-500^{\circ} \mathrm{C} \\
0.001-1.0 \mathrm{~s}^{-1}\end{array}$ & $\begin{array}{l}\text { Wenchen } \\
\text { et al. [69] }\end{array}$ \\
\hline $\mathrm{AA} 6061 / \mathrm{B}_{4} \mathrm{C}$ & 152 & 6.9 & $\begin{array}{l}360-510^{\circ} \mathrm{C} \\
0.001-1.0 \mathrm{~s}^{-1}\end{array}$ & Kaikai et al. [70] \\
\hline $8009 \mathrm{Al} / \mathrm{Al}_{2} \mathrm{O}_{3}$ & 509 & 7.9 & $\begin{array}{l}400-500^{\circ} \mathrm{C} \\
0.001-1.0 \mathrm{~s}^{-1}\end{array}$ & Shuang et al. [71] \\
\hline $2024 \mathrm{Al} / \mathrm{CNT}$ & 322 & 7.09 & $\begin{array}{l}200-400^{\circ} \mathrm{C} \\
0.001-1.0 \mathrm{~s}^{-1}\end{array}$ & Mokdad et. al. [72] \\
\hline $8009 \mathrm{Al} / \mathrm{SiC}$ & 495 & 7.75 & $\begin{array}{l}400-500^{\circ} \mathrm{C} \\
0.001-1.0 \mathrm{~s}^{-1}\end{array}$ & Shuang et al. [15] \\
\hline $\mathrm{Al} 6061 / \mathrm{B}_{4} \mathrm{C}$ & 186 & 7.4 & $\begin{array}{l}380-530^{\circ} \mathrm{C} \\
0.001-1.0 \mathrm{~s}^{-1}\end{array}$ & Yu-Lili et al. [73] \\
\hline AA $6061 / 10 \% \mathrm{SiC}$ & 231 & 8.44 & $\begin{array}{l}300-500^{\circ} \mathrm{C} \\
0.001-1.0 \mathrm{~s}^{-1}\end{array}$ & Xiaopu et.al. [74] \\
\hline AA6N01 & 367.57 & 11.16 & $\begin{array}{l}500-550^{\circ} \mathrm{C} \\
0.01-10 \mathrm{~s}^{-1}\end{array}$ & Dong et al. [18] \\
\hline $\mathrm{AA} 7075 / \mathrm{Al}_{2} \mathrm{O}_{3}$ & 289 & 2.4 & $\begin{array}{l}350-500^{\circ} \mathrm{C} \\
0.001-1.0 \mathrm{~s}^{-1}\end{array}$ & Ezatpor et al. [75] \\
\hline $\mathrm{AA} 7075 / \mathrm{Al}_{2} \mathrm{O}_{3}$ & 307 & 6.4 & $\begin{array}{l}300-500^{\circ} \mathrm{C} \\
0.001-1.0 \mathrm{~s}^{-1}\end{array}$ & $\begin{array}{l}\text { Saravanan } \\
\text { et al. [76] }\end{array}$ \\
\hline $\mathrm{Al} / \mathrm{Al}_{2} \mathrm{O}_{3}$ & 360 & 20.83 & $\begin{array}{l}300-450^{\circ} \mathrm{C} \\
0.001-1.0 \mathrm{~s}^{-1}\end{array}$ & Baifeng et. al. [77] \\
\hline $2024 \mathrm{Al} / 30 \% \mathrm{SiCp}$ & 153 & 7.88 & $\begin{array}{l}350-500^{\circ} \mathrm{C} \\
0.01-10 \mathrm{~s}^{-1}\end{array}$ & Hao et. al. [16] \\
\hline $7050 \mathrm{Al} / \mathrm{TiB}_{2}$ & 142 & 4.66 & $\begin{array}{l}300-450^{\circ} \mathrm{C} \\
0.001-1.0 \mathrm{~s}^{-1}\end{array}$ & Mingliang et al. [78] \\
\hline $\mathrm{Al} 6063 / \mathrm{al}_{2} 0_{3} / \mathrm{Y}_{2} \mathrm{O}_{3}$ & -181000 & 3.9 & $\begin{array}{l}350-500^{\circ} \mathrm{C} \\
0.001-1.0 \mathrm{~s}^{-1}\end{array}$ & Ahmed et al. [48] \\
\hline $6061 / \mathrm{B}_{4} \mathrm{Cp}$ & 149 & 2.5 & $\begin{array}{l}300-500^{\circ} \mathrm{C} \\
0.001-1.0 \mathrm{~s}^{-1}\end{array}$ & Huizhong et al. [79] \\
\hline $2014 \mathrm{Al} / 20 \% \mathrm{SiCp}$ & 279 & 7.614 & $\begin{array}{l}400-475^{\circ} \mathrm{C} \\
1-10^{-2} \mathrm{~s}^{-1}\end{array}$ & Shao et al. [80] \\
\hline $6061 \mathrm{Al} / 20 \% \mathrm{Al}_{2} 0_{3}$ & 155 & 7.23 & $\begin{array}{l}350-500^{\circ} \mathrm{C} \\
0.001-1.0 \mathrm{~s}^{-1}\end{array}$ & Spigarelli et al. [81] \\
\hline AA 6060 & 161 & 4.7 & $\begin{array}{l}300-500^{\circ} \mathrm{C} \\
0.001-1.0 \mathrm{~s}^{-1}\end{array}$ & Mcqueen and Lee[82] \\
\hline Aa6061 & 145 & 3.55 & $\begin{array}{l}300-500^{\circ} \mathrm{C} \\
0.001-1.0 \mathrm{~s}^{-1}\end{array}$ & Shepperd [83] \\
\hline AA 6063 & 142 & 5.385 & $\begin{array}{l}300-500^{\circ} \mathrm{C} \\
0.001-1.0 \mathrm{~s}^{-1}\end{array}$ & Velay [84] \\
\hline
\end{tabular}




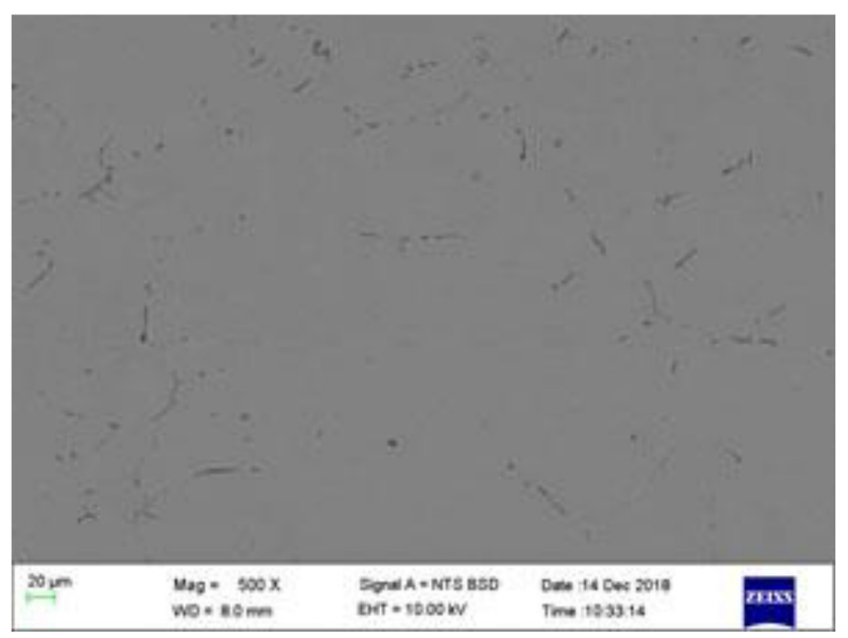

Sample 1: $400^{\circ} \mathrm{C} / 0.01 \mathrm{~s}^{-1}$

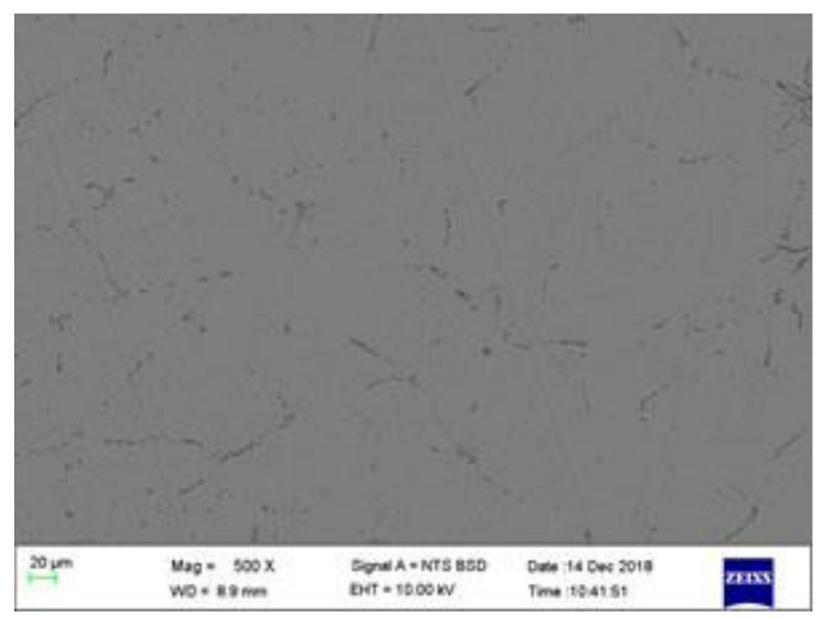

Sample $2: 350^{\circ} \mathrm{C} / 0.01 \mathrm{~s}^{-1}$

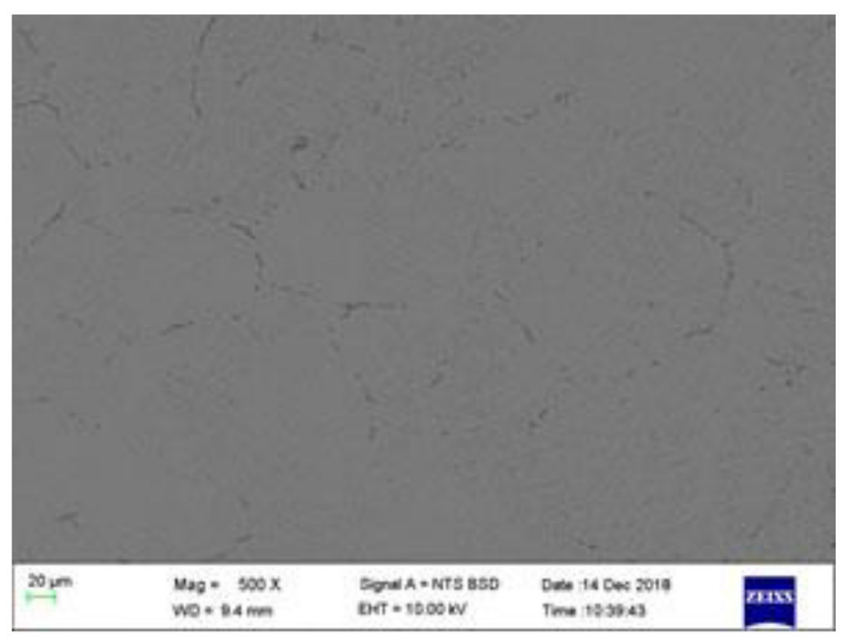

Sample 3: $300^{\circ} \mathrm{C} / 0.1 \mathrm{~s}^{-1}$

Fig. 7. As-deformed microstructures of samples 1-3.

\subsection{Post-deformation microstructure}

Figures 7-9 show the SEM images of the deformed samples under the different deformation conditions. It can be seen that similar features were exhibited under the different deformation conditions. The SEM images did not quite show very distinct microstructural features which could help in confirming the dynamic softening mechanism. This necessitated the use of image $\mathrm{J}$ freeware processed microstructures to assess the difference in microstructures (Fig. 10). From Figure 10, it can be argued that the samples deformed at $350^{\circ} \mathrm{C}$ using $0.01 \mathrm{~s}^{-1}$ strain rate (Fig. 10a) showed more signs of well-defined equiaxed grains, suggestive of dynamic recrystallization compared to that of $1.0 \mathrm{~s}^{-1}$ strain rate (Fig. 10b) which points to dynamic recovery. Notwithstanding, more indepth microstructural evaluation using EBSD and possibly, In situ hot deformation on a SEM to follow the microstructural evolution would be required to confirm the dynamic softening mechanism(s). This the authors intend to explore in further investigation of this $\mathrm{Al}$ based composite system. However, from the flow stress patterns observed in Figure 1, and the activation energies computed for the composite (Table 4), the authors propose that dynamic recrystallization and/or dislocations-reinforcements interactions are the dominant deformation mechanism at strain rates of 0.01 and $0.1 \mathrm{~s}^{-1}$ while dynamic recovery is prevalent at $1 \mathrm{~s}^{-1}$ strain rate. 


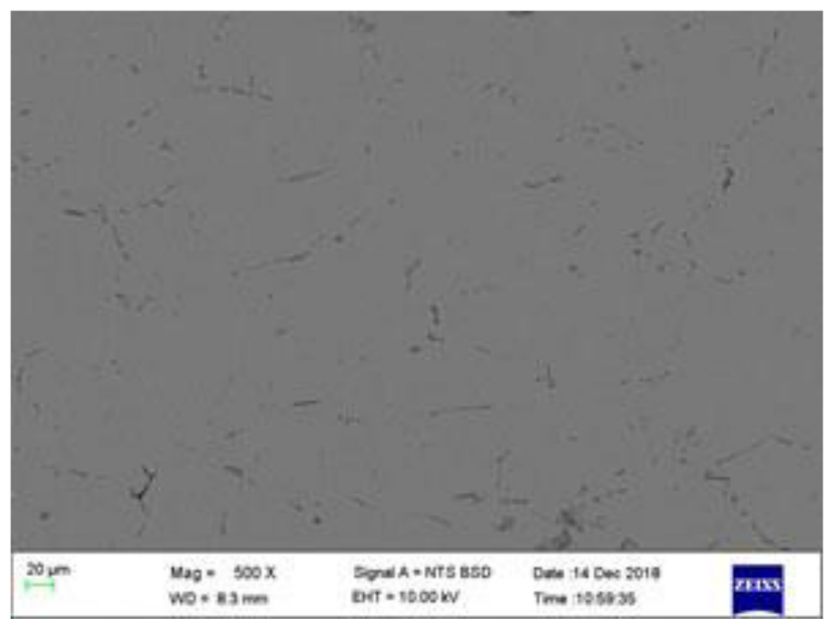

Sample 4: $400^{\circ} \mathrm{C} / 0.1 \mathrm{~s}^{-1}$

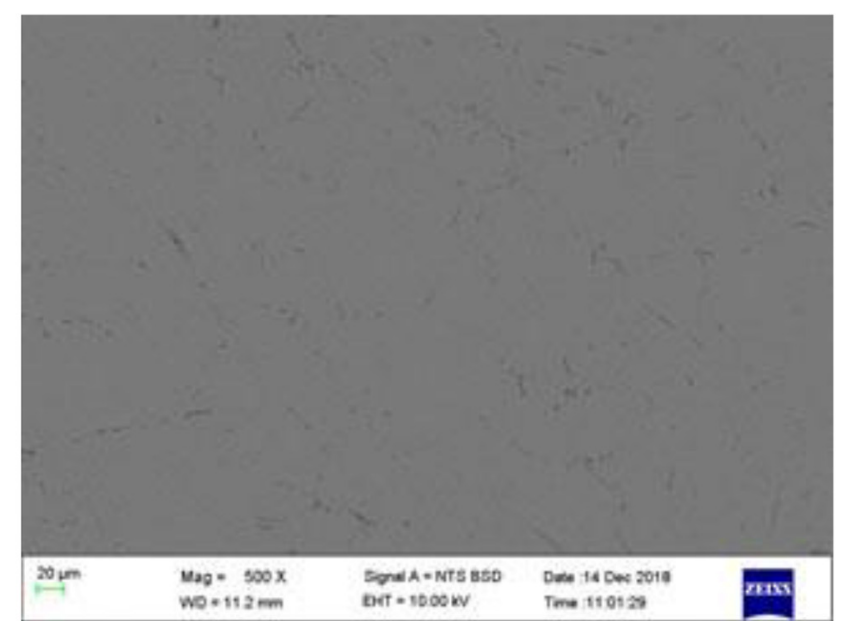

Sample 5: $350^{\circ} \mathrm{C} / 0.1 \mathrm{~s}^{-1}$

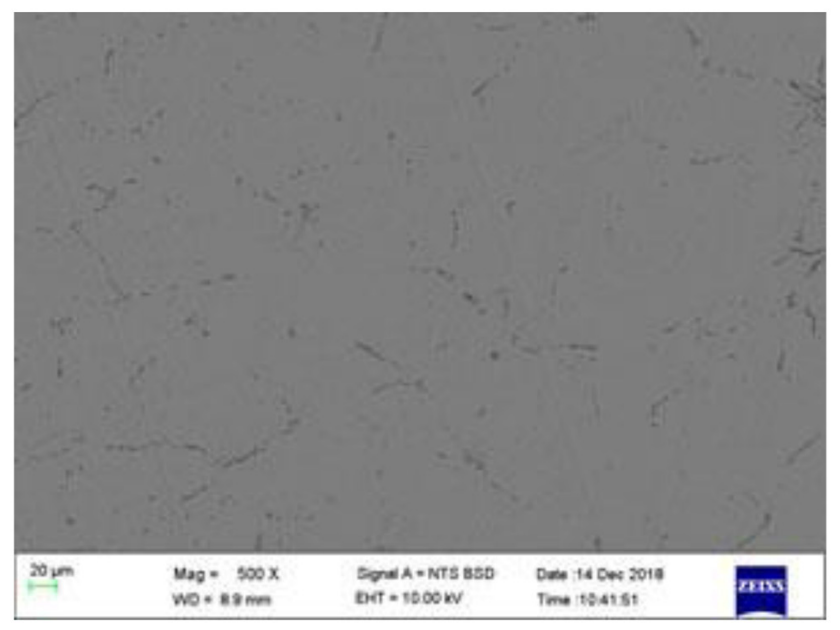

Sample 6: $300^{\circ} \mathrm{C} / 0.1 \mathrm{~s}^{-1}$

Fig. 8. As-deformed microstructures of samples 4-6.

\section{Conclusion}

The hot deformation behaviour of Al6063 matrix composite reinforced with 8 wt. \% bamboo leave ash (BLA) and silicon carbide ( $\mathrm{SiC}$ ) (in ratio 1:3) was investigated in this study at temperatures of 300,350 , and $400^{\circ} \mathrm{C}$ and strain rates of $0.01,0.1$, and $1 \mathrm{~s}^{-1}$. The results show that:

- The flow stress increased with increasing strain rate from $0.01 \mathrm{~s}^{-1}$ to $0.1 \mathrm{~s}^{-1}$ but with marginal changes between $0.1 \mathrm{~s}^{-1}$ and $1.0 \mathrm{~s}^{-1}$; while the flow stress increased with decreasing deformation temperatures.

- The flow patterns suggested that at low strain rates of 0.01 and $0.1 \mathrm{~s}^{-1}$, dynamic recrystallisation and/or dislocations-reinforcements interaction were the probable dominant deformation mechanisms, which is supported fairly by the activation energy value
( $290.5 \mathrm{~kJ} / \mathrm{mol})$, that was $52 \%$ higher than that for selfdiffusion of Aluminium $(142 \mathrm{~kJ} / \mathrm{mol})$; while at $1 \mathrm{~s}^{-1}$, dynamic recovery seemed to predominate.

- The workability of the composite which was measured by the activation energy for hot working of the composite, established using Arrhenius hyperbolic-sine equation to be $\sim 290.5 \mathrm{~kJ} / \mathrm{mol}$, was considered to be reasonable, as it falls within the range of $110-509 \mathrm{~kJ} /$ mol, reported in literature for other aluminium matrix composites.

This work was supported through the AESA RISE Postdoctoral Fellowship (ARPDF) [Grant No: ARPDF-18-03] implemented by the African Academy of Sciences (AAS) through funding from the Carnegie Corporation of New York. The statements made, and views expressed in this work are solely the responsibility of the authors. 


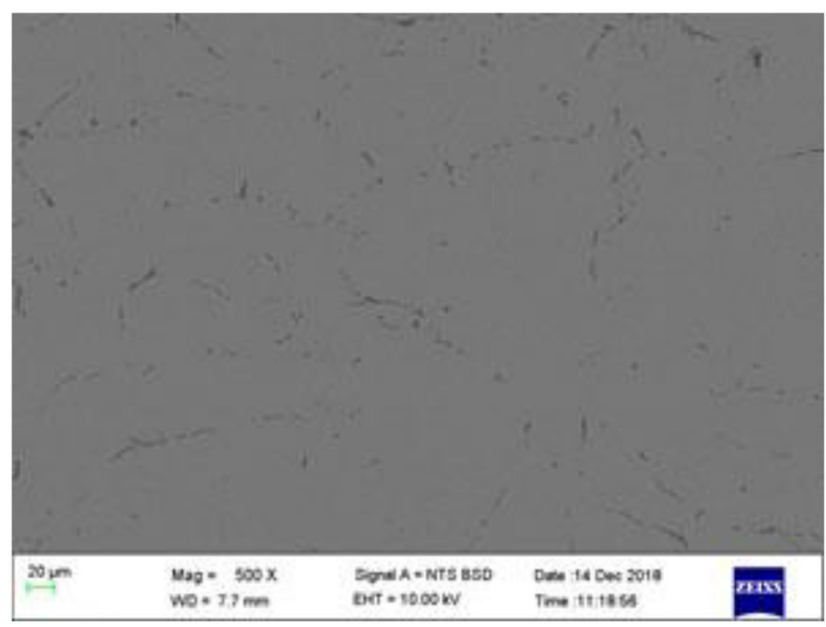

Sample 7: $400^{\circ} \mathrm{C} / 1 \mathrm{~s}^{-1}$

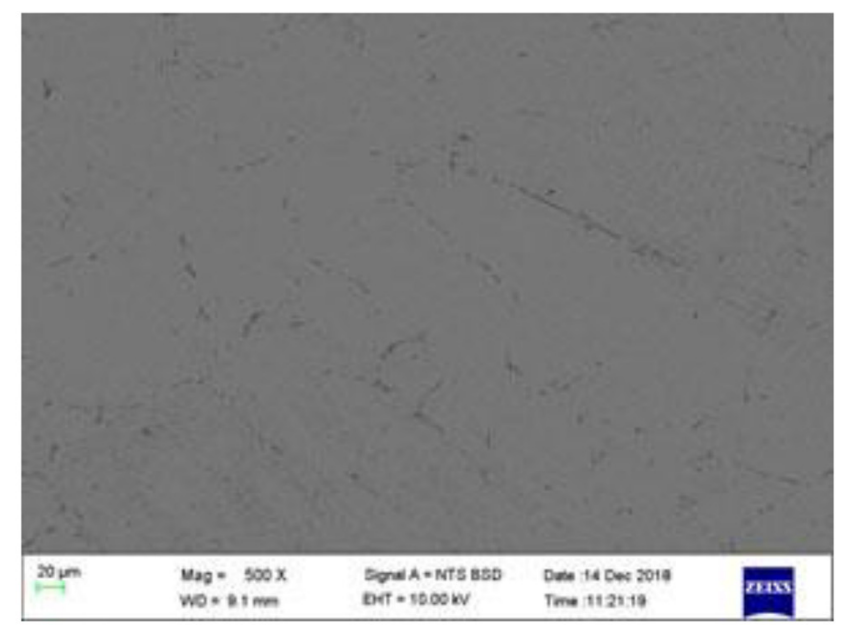

Sample 8: $350^{\circ} \mathrm{C} / 1 \mathrm{~s}^{-1}$

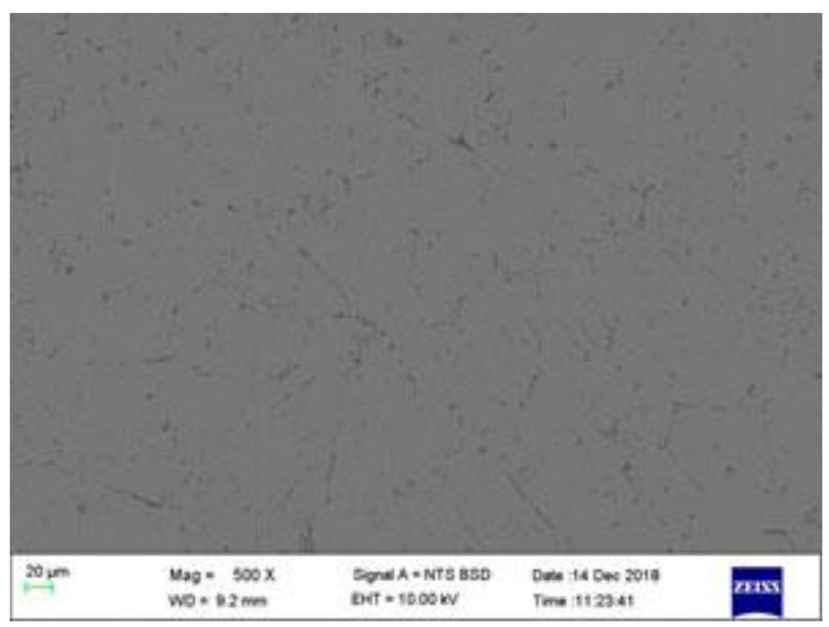

Sample 9: $300^{\circ} \mathrm{C} / 1 \mathrm{~s}^{-1}$

Fig. 9. As-deformed microstructures of samples 7-9.

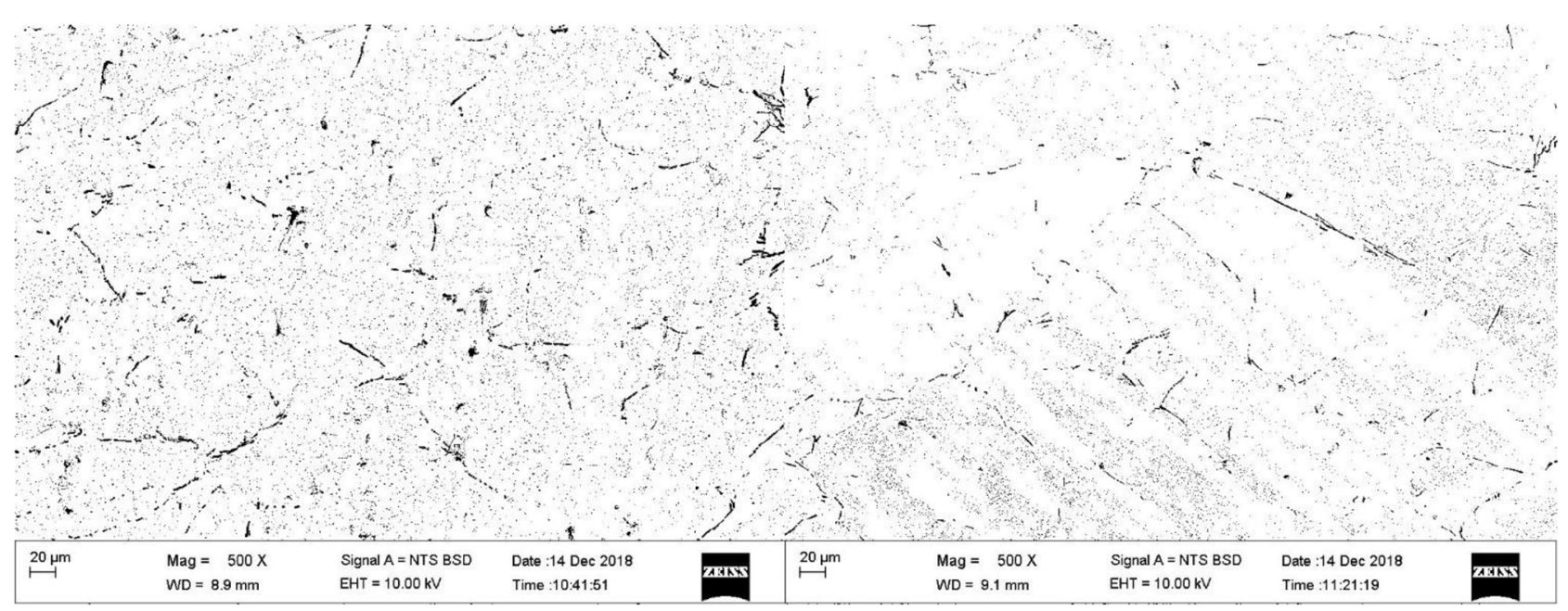

Figure 10a : 350/0.01s ${ }^{-1}$

Figure $10 \mathrm{~b}: 350 / 1 \mathrm{~s}^{-1}$

Fig. 10. Imagej software processed images of composite (a) as-deformed at $350{ }^{\circ} \mathrm{C} / 0.01 \mathrm{~s}^{-1}$, and (b) as-deformed at $350{ }^{\circ} \mathrm{C} / 1 \mathrm{~s}^{-1}$. 


\section{References}

1. A. Inegbenebor, C. Bolu, P. Babalola, A. Inegbenebor, O. Fayomi, Aluminium silicon carbide particulate metal matrix composite development via stir casting processing, Silicon 10 (2018) 343-347

2. M. Abdulwahab, O. Umaru, M. Bawa, H. Jibo, Microstructural and thermal study of Al-Si-Mg alloy/melon shell ash particulate composite, Results Phys. 7 (2017) 974-954

3. K.K. Alaneme, A.O. Aluko, Fracture toughness $\left(\mathrm{K}_{\mathrm{IC}}\right)$ and tensile properties of as-cast and age-hardened aluminium (6063)-silicon carbide particulate composites, Sci. Iran. Trans. A 9 (2012) 992-996.

4. D. Isaac, K. Kumaravel, M. Nadarajan, Influence of rice husk ask particles on microstructure and tensile behavior of AA6061 aluminum matrix composites produced using friction stir processing, Compos Commun. 3 (2017) 42-46

5. M.O. Bodunrin, K.K. Alaneme, L.H. Chown, Aluminum matrix hybrid composite. A review of reinforcement philosophies; mechanical, corrosion ant tribological characteristics, J. Mater. Res. Technol. 4 (2015) 434-445.

6. K.K. Alaneme, I.B. Akintunde, P.A. Olubambi, T.M. Adewale, Mechanical behaviour of rice husk ash - alumina hybrid reinforced aluminium based matrix composites, J. Mater. Res. Technol. 2 (2013) 60-67

7. A. Devaraju Kumar, A. Kotiveerachari, Influence of addition of $\mathrm{Grp} / \mathrm{Al}_{2} \mathrm{O}_{3}$ with $\mathrm{SiCp}$ on wear properties of aluminum alloy 6061-T6 hybrid composites via friction stir processing, Trans. Nonferrous Met. Soc. China 23 (2013) $1275-1280$.

8. X. Chen Fu, D. Teng, J.H. Zhang, Hot deformation behavior and mechanism of hybrid aluminum-matrix composites reinforced with micro-SiC and nano-TiB2, J. Alloys Compd. 753 (2018) 566-575.

9. L. Saravanan, T. Senthilvelan, Investigations on the hot workability characteristics and deformation mechanisms of aluminium alloy- $\mathrm{Al}_{2} \mathrm{O}_{3}$ nanocomposite, Mater. Des. 79 (2015) 6-14

10. K. Wang, X. Li, G. Shu, G. Tang, Hot deformation behavior and microstructural evolution of particulate reinforced AA6061 $/ \mathrm{B}_{4} \mathrm{C}$ composite during compression at elevated temperature, Mater Sci. \& Eng. A. 696 (2017) 248-256

11. S. Chen, J. Teng, H. Luo, Y. Wang, H. Zhang, Hot deformation characteristics and mechanism of PM 8009Al/ $\mathrm{SiC}$ particle reinforced composites, Mater. Sci. Eng. A. 697 (2017) 194-202

12. R. Tao, Y. Zhao, X. Kai, Z. Zhao, R. Ding, L. Liang, W. Xu, Effects of hot rolling deformation on the microstructure and tensile properties of an in situ-generated ZrB2 nanoparticlereinforced AA6111 composite, Mater Sci \& Eng. A. 732 (2018) 138-147

13. Z.Y. Huang, X.X. Zhang, B.L. Xiao, Z.Y. Ma, Hot deformation mechanisms and microstructure evolution of $\mathrm{SiCp} / 2014 \mathrm{Al}$ composite, J. Alloys \& Compd. 722 (2017) $145-157$

14. K.K. Alaneme, B.O. Ademilua, M.O. Bodunrin, Mechanical and corrosion Behaviour of Bamboo Leaf Ash-Silicon Carbide Hybrid Composites, Trib. in Ind. 35 (2013) 25-35.

15. C. Shuang, T. Jie, L. Haibo, W. Yu, Z. Hui, Hot deformation characteristics and mechanism of PM $8009 \mathrm{Al} / \mathrm{SiC}$ particle reinforced composites. Mater. Sci. \& Eng. A. 697 (2017) 194-202
16. S. Hao, et al. Hot deformation behaviors of $35 \% \mathrm{SiCp} / 2024 \mathrm{Al}$ metal matrix composites. Trans. Nonferrous Met. Soc. China. 24 (2014) 2468-2474

17. Y. Yang, Z. Zhang, X. Zhang, Processing map of Al2O3 particulate reinforced $\mathrm{Al}$ alloy matrix composites. Mater. Sci. Eng. A. 558 (2012) 112-118

18. Y. Dong, C. Zhang, G. Zhao, Y. Guan, A. Gao, W. Sun, Constitutive equation and processing maps of an $\mathrm{Al}-\mathrm{Mg}-\mathrm{Si}$ aluminum alloy: determination and application in simulating extrusion process of complex profiles, Mater. Des. 92 (2016) 983-997

19. T. Mitchell, E. Hirth, A. Misra, Apparent activation energy and stress exponent in materials with a high Peierls stress. Acta Mater. 50 (2002) 1087-1093

20. Y. Chen, A.H. Clausen, O.S. Hopperstad, M. Langseth, Stress-Strain Behaviour Of Aluminium Alloys at A Wide Range of Strain Rates, Int. J. Solids Struct. 2009, 46, Pp. 3825-3835

21. F. Kabirian, A. Khan, A. Pandey, Negative to positive strain rate sensitivity in 5xxx series aluminum alloys: Experiment and constitutive modeling. Int. J. Plast. 55 (2014) 232-246

22. H. Yamada, T. Kami, R. Mori, T. Kudo, M. Okada, Strain Rate Dependence of Material Strength in AA5xxx Series Aluminum Alloys and Evaluation of Their Constitutive Equation. Metals. 8 (2018) 1-15

23. Y. Zong, Y.D.B. Shan, M. Xu, Y. Lv, Flow softening and microstructural evolution of TC11 titanium alloy during hot deformation. J. Mater. Process. Technol. 209 (2009) 1988-1994

24. W.D. Nix, High Temperature Deformation Processes and Strengthening Mechanisms in Intermetallic Particulate Composites (Defense Technical Information Center, 1991). doi:10.21236/ADA232737

25. J. Yan, Q. Pan, A. Li, W. Song, Flow behavior of Al-6.2Zn$0.70 \mathrm{Mg}-0.30 \mathrm{Mn}-0.17 \mathrm{Zr}$ alloy during hot compressive deformation based on Arrhenius and ANN models. Trans. Nonferrous Met. Soc. China 27 (2017) 638-647

26. H. Chen, C. Cao, Characterization of hot deformation microstructures of alpha-beta titanium alloy with equiaxed structure. Trans. Nonferrous Met. Soc. China. 22 (2012) 503-509

27. Y. Lin, C.X.M. Chen, A critical review of experimental results and constitutive descriptions for metals and alloys in hot working. Mater. Des. 32 (2011) 1733-1759

28. K.K. Alaneme, E.A. Okotete, V.A. Fajemisin, M.A. Bodunrin, Applicability of metallic reinforcements for mechanical performance enhancement in metal matrix composites: a review, Arab. J. Basic Appl. Sci. 26 (2019) 311-330

29. H. Wu, H. Zhang, S. Chen, D. Fu, Flow stress behavior and processing map of extruded $7075 \mathrm{Al} / \mathrm{SiC}$ particle reinforced composite prepared by spray deposition during hot compression. Trans. Nonferrous Met. Soc. China. 25 (2015) 692-698

30. X.G. Fan, Y. Zhang, P.F. Gao, Z.N. Lei, M. Zhan, Deformation behavior and microstructure evolution during hot working of a coarse-grained Ti-5Al-5Mo-5V-3Cr-1Zr titanium alloy in beta phase field. Mater. Sci. Eng. A. 694 (2017) 24-32

31. M.O. Bodunrin, L.H. Chown, J.W. Van der merwe, K.K. Alaneme, Hot working of Ti-6Al-4V with a complex initial microstructure. Int. J. Mater. Form. 2018, doi:10.1007/ s12289-018-1457-9. 
32. C.M. Sellars, W.J. Tegart, On the mechanism of hot deformation. Acta Metall. 14 (1966) 1136-1138

33. M.J. Luton, C.M. Sellars, Dynamic recrystallization in nickel and nickel-iron alloys during high temperature deformation. Acta Metall. 17 (1969) 1033-1043

34. R.D. Doherty, et al. Current issues in recrystallization: a review. Mater. Sci. Eng. A. 238 (1997) 219-274

35. W. Peng, W. Zeng, Q. Wang, H. Yu, Comparative study on constitutive relationship of as-cast Ti60 titanium alloy during hot deformation based on Arrhenius-type and artificial neural network models. Mater. Des. 51 (2013) 95-104

36. J.K. Fan, H.C. Kou, M.J. Lai, B. Tang, H. Chang, J.S. Li, Characterization of hot deformation behavior of a new near beta titanium alloy: Ti-7333. Mater. Des. 49 (2013) 945-952

37. M. Härtel, C. Illgen, P. Frint, M. Wagner, On the PLC Effect in a Particle Reinforced AA2017 Alloy, Metals 8 (2018) 88

38. I. Philippart, H.J. Rack, High temperature dynamic yielding in metastable Ti-6.8 Mo-4.5 F-1.5 Al. Mater. Sci. Eng. A. 243 (1988) 196-200

39. G.E. Dieter, H.A. Kuhn, S.L. Semiatin, Handbook of workability and process design, ASM International, 2003

40. S.D. Mesarovic, Dynamic strain aging and plastic instabilities. J. Mech. Phys. Solids. 43 (1995) 671-700

41. H. Shi, A. Mclaren, A. Sellars, C.M.R. Shahani, Bolingbroke R. Constitutive equations for high temperature flow stress of aluminium alloys. Mater. Sci. Technol. 13 (1997) 210-216

42. D. Ponge, M. Bredehöft, G. Gottstein, Dynamic recrystallization in high purity aluminum, Scr. Mater. 37 (1997) 1769-1775

43. C. Shi, W. Mao, X.G. Chen, Evolution of activation energy during hot deformation of AA7150 aluminum alloy, Mater. Sci. Eng. A. 571 (2013) 83-91

44. J. Zhang, B. Chen, Z. Baoxiang, Effect of initial microstructure on the hot compression deformation behavior of a 2219 aluminum alloy, Mater. Des. 34 (2012) 15-21

45. Q. Yang, et al. Effects of strain rate on flow stress behavior and dynamic recrystallization mechanism of $\mathrm{Al}-\mathrm{Zn}-\mathrm{Mg}-\mathrm{Cu}$ aluminum alloy during hot deformation. Mater. Sci. Eng. A. 662 (2016) 204-213

46. D. Li, et al. Dynamic recrystallization behavior of 7085 aluminum alloy during hot deformation. Trans. Nonferrous Met. Soc. China. 26 (2016) 1491-1497

47. H.J. Mcqueen, D.L. Bourell, Hot Workability of Metals and Alloys. JOM. 39 (1987) 28-35

48. H. Li, H. Wang, M. Zeng, X. Liang, H. Liu, Forming behavior and workability of 6061/B4CP composite during hot deformation, Compos. Sci. Technol. 71 (2011) 925-930

49. H. Ahamed, V. Senthilkumar, Hot deformation behavior of mechanically alloyed Al6063/0.75Al2O3/0.75Y2O3 nanocomposite-A study using constitutive modeling and processing map. Mater. Sci. Eng. A. 539 (2012) 349-359

50. J. Cai, K. Wang, P. Zhai, F. Li, J. Yang, A Modified JohnsonCook Constitutive Equation to Predict Hot Deformation Behavior of Ti-6Al-4V Alloy, J. Mater. Eng. Perform. 24 (2014) 32-44

51. J. Cai, K. Wang, P. Zhai, F. Li, J. Yang, A modified Johnsoncook Constitutive Equation to predict Hot Deformation Behaviour of Ti- 6Al- 4V Alloy, J. Mater. Eng. Perform. 24 (2017) 32-44
52. L. Briottet, J.J. Jonas, F. Montheillet, A mechanical interpretation of the activation energy of high temperature deformation in two phase materials, Acta Mater. 44 (1966) $1665-1672$

53. R.K.C. Nkhoma, C.W. Siyasiya, F.W.E. Stump, Hot workability of AISI 321 and AISI 304 austenitic stainless steels. J. Alloys Compd. 595 (2014) 103-112

54. Y. Deng, C. Zhang, G. Zhao, Y. Guan, A. Gao, W. Sun, Constitutive equation and processing maps of an $\mathrm{Al}-\mathrm{Mg}-\mathrm{Si}$ aluminum alloy: Determination and application in simulating extrusion process of complex profiles. Mater. Des. 92 (2016) 983-997

55. E. Evangelista, H.J. Mcqueen, N.D. Ryan, Hot strength, dynamic recovery and dynamic recrystallization of 317 type stainless steel Metallurgical Science and Technology. Metall. Sci. Technol. 5 (1987) 50-58

56. H.J. Mcqueen, Development of dynamic recrystallization theory. Mater. Sci. Eng. A. 387-389 (2004) 203-208.

57. S.B. Davenport, N.J. Silk, C.N. Sparks, C.M. Sellars, Development of constitutive equations for modelling of hot rolling. Mater. Sci. Technol. 16 (2000) 539-546

58. Z. Zeng, S. Jonsson, Y. Zhang, Constitutive equations for pure titanium at elevated temperatures. Mater. Sci. Eng. A. 505 (2009) 116-119

59. S. Mandal, V. Rakesh, P.V. Sivaprasad, S. Venugopal, K.V. Kasiviswanathan, Constitutive equations to predict high temperature flow stress in a Ti-modified austenitic stainless steel. Mater. Sci. Eng. A. 500 (2009) 114-121

60. G. Ge, et al. Constitutive modeling of high temperature flow behavior in a Ti-45Al-8Nb-2Cr-2Mn-0.2Y alloy. Sci. Rep. 8 (2018) 5453

61. W.A. Bryant, Correlation of data on the hot deformation of Ti-6Al-4V. J. Mater. Sci. 10 (1975) 1793-1797

62. A. Momeni, S.M. Abbasi, Effect of hot working on flow behavior of Ti-6Al-4V alloy in single phase and two-phase regions, Mater. Des. 31 (2010) 3599-3604

63. H.J. Mcqueen, N.D. Ryan, Constitutive analysis in hot working, Mater. Sci. Eng. A 322, 43-63

64. H.J. McQueen, W.A. Wong, J.J. Jonas, Deformation of Aluminium at High Temperatures and Strain Rates, Can. J. Phys. 45 (1967) 1225-1234

65. H.J. Mcqueen, S. Yue, N.D. Ryan, E. Fry, Hot working characteristics of steels in austenitic state, J. Mater. Process. Technol. 53 (1995) 293-310

66. W. Xu, X. Jin, W. Xiong, X. Zeng, Shan, Study on hot deformation behavior and workability of squeeze-cast $20 \mathrm{vol}$ $\% \mathrm{SiCw} / 6061 \mathrm{Al}$ composites using processing map, Mater. Charact. 135 (2018) 154-166

67. D.J. Prozexky, M.O. Bodunrin, L.H. Chown, Hot deformation behaviour of $\alpha+\beta$ Ti-Al-V-Fe experimental alloys, AIP Conf. Proc. 1896 (2017) 160019

68. T. Ran, Z. Yutao, K. Xizhou, Z. Zhihao, D. Renfa, L. Liang, $\mathrm{X}$. Weitai, Effects of hot rolling deformation on the microstructure and tensile properties of an in situ-generated ZrB2 nanoparticle-reinforced AA6111composite. Mater. Sci. \& Eng. A. 732 (2018) 138-147

69. X. Wenchen, J. Xueze, X. Wendeng, Z. Xiangqian, S. Debin, Study on hot deformation behavior and workability of squeeze-cast $20 \mathrm{vol} \% \mathrm{SiCw} / 6061 \mathrm{Al}$ composites using processing map, Mater. Charac. 135 (2018) 154-166 
70. W. Kaikai, L. Xiaopei, L. Qiulin, S. Guogang, T. Guoyi, Hot deformation behavior and microstructural evolution of particulate reinforced AA6061/B4C composite during compression at elevated temperature, Mater. Sci. \& Eng. A. 696 (2017) 248-256

71. C. Shuang, T. Jie, L. Haibo, W. Yu, Z. Hui, Hot deformation characteristics and mechanism of $\mathrm{PM} 8009 \mathrm{Al} / \mathrm{Al}_{2} 0_{3}$ particle reinforced composites, Mater. Sci. \& Eng. A. 697 (2017) 194-202

72. F. Mokdad, D.L. Chen, Z.Y. Liu, D.R. Ni, B.L. Xiao, Z.Y. $\mathrm{Ma}$, Hot deformation and activation energy of a CNTreinforced aluminum matrix nanocomposite, Mater. Sci. \& Eng. A. 695 (2017) 322-331

73. L. Yu, X. Wen, Z. Jun, C. Hongsheng, Hot deformation behaviors and processing maps of $\mathrm{B} 4 \mathrm{C} / \mathrm{Al} 6061$ neutron absorber composites, Mater. Charac. 124 (2017) 107-116

74. L. Xiaopu, L. Chongyu, L. Kun, M. Mingzhen, L. Riping, Hot Deformation Behaviour of SiC/AA6061 Composites Prepared by Spark Plasma Sintering, J. Mater. Sci. \& Tech. 32 (2016) 291-297

75. Hr. Ezatpour, A. Chaichi, S.A. Sajjadi, The effect of $\mathrm{Al}_{2} \mathrm{O}_{3^{-}}$ nanoparticles as the reinforcement additive on the hot deformation behavior of 7075 aluminum alloy, Mater. \& Des. 88 (2015) 1049-1056

76. L. Saravanan, T. Senthilvelan, Investigations on the hot workability characteristics and deformation mechanisms of aluminium alloy-Al2O3 nanocomposite, Mater \& Des. 79 (2015) 6-14
77. L. Baifeng, Q. Risheng, L. Chunhong, Y. Xiaofang, L. Zhiqiang, Z. Di, L. Qing, Hot deformation and processing maps of $\mathrm{Al}_{2} \mathrm{O}_{3} / \mathrm{Al}$ composites fabricated by flake powder metallurgy, Trans. Nonferrous Met. Soc. China. 25 (2015) $1056-1063$

78. W. Mingliang, C. Zhe, C. Dong, W. Yi, L. Xianfeng, M. Naiheng, W. Haowei, The Constitutive Model and Processing Map for in-situ 5wt\% Tib 2 Reinforce 7050 Al Alloy Matrix Composite, Trans. Tech. Pub. 575-576 (2014) 11-19

79. L. Huizhong, W. Haijun, Z. Min, L. Xiaopeng, L. Hongting, forming behavior and workability of 6061 /B4CP composite during hot deformation, Comp. Sci. \& Tech. 71 (2011) 925-930

80. J.C. Shao, B.L. Xiao, Q.Y. Wang, Z.Y. Ma, Y. Liu, K. Yang, Constitutive flow behavior and hot workability of powder metallurgy processed 20 vol.\% $\mathrm{SiCp} / 2024 \mathrm{Al}$ composite, Mater. Sci. \& Eng. A 527 (2010) 7865-7872

81. S. Spigarelli, E. Cerri, P. Cavaliere, E. Evangelista, An analysis of hot formability of the $6061+20 \% \mathrm{Al}_{2} \mathrm{O}_{3}$ composite by means of different stability criteria, Mater. Sci. \& Eng. A. 327 (2002) 144-154

82. H.J. Mcqueen, M.J. Lee, Light metals 2000 In: J. Kazadi et al. (Eds.). Met. Soc. CIM, Montreal 2000, 529-538

83. T. Sheppard, Extrusion of Aluminum Alloys. Kluwer Academic Publishers, 1999

84. X. Velay, Prediction and control of subgrain size in the hot extrusion of aluminium alloys with feeder plates. J. Mater. Process. Tech. 2008

Cite this article as: Kenneth Kanayo Alaneme, Saheed Adeoye Babalola, Lesley Heath Chown, Michael Oluwatosin Bodunrin, Hot deformation behaviour of bamboo leaf ash-silicon carbide hybrid reinforced aluminium based composite, Manufacturing Rev. $7,17(2020)$ 